\title{
Predicting integrated thermal and acoustic performance in naturally ventilated high-rise buildings using CFD and FEM simulation
}

\author{
Xiang Yu ${ }^{\mathrm{a}}$, Qide Zhang ${ }^{\mathrm{a}}$, Jian Kang ${ }^{\mathrm{b}}$ and Fangsen Cui ${ }^{\mathrm{a}^{*}}$ \\ ${ }^{a}$ Institute of High Performance Computing, Agency for Science, Technology and Research \\ (A*STAR), Singapore 138632 \\ ${ }^{\mathrm{b}}$ School of Architecture, University of Sheffield, United Kingdom \\ cuifs@ihpc.a-star.edu.sg \\ *Correspondence Author
}

\begin{abstract}
:
The study of ventilation windows for both natural ventilation and noise mitigation has drawn significant attention recently. This paper presents the numerical approaches to analyse the integrated thermal and acoustical performance of ventilation windows, for a residential building in tropical climate which employs double-layer noise mitigation window for natural ventilation. Given a set of outdoor wind conditions, the distributions of indoor flow and temperature fields are calculated using Computational Fluid Dynamics (CFD) simulation. The thermal comfort is evaluated using statistical Predicted Mean Vote (PMV) method. For the acoustic performance, noise radiation from road traffic is assumed as the noise source, and the sound insulation of building façade is simulated using Finite Element Method (FEM). From the simulation results, it is found that the thermal satisfaction response is closely related to the inlet wind temperature and speed, and the window opening size greatly affects the ventilation performance. From the case study in Singapore, during certain season, day/night time and with sufficient wind flow, the ventilation window can provide enough fresh air, maintain adequate thermal comfort and quiet acoustic environment for the occupants. The numerical approaches presented in this paper are applicable to general window design studies, and the simulation findings can be incorporated into green building planning. The advantages of using simulation approaches are highlighted and their limitations are discussed.
\end{abstract}

Key words: natural ventilation; thermal comfort; ventilation window; sound insulation.

2018 Building Simulation

Date received: 11 July 2017 Date accepted: 26 October 2017

Publish online: 17 November 2017

\section{Introduction}

Ventilation of building constitutes one of the main energy consumptions in the building sector. In the context of sustainable development and green building, reducing heavy reliance on electro-mechanical ventilation and air-conditioning becomes a major trend. Natural ventilation has the potential to minimize energy use, reduce operation cost and improve indoor air quality . Awbi (2003) introduced the general concept of building ventilation and reviewed 
some critical factors affecting the comfort of occupant. As building windows are often used as the primary device for natural ventilation, the study of ventilation windows is of practical interest and continuously attracting researcher's attention.

In the development of building ventilation system, computer simulation can provide a useful tool. With sufficiently accurate simulation model, designers and architects can predict and efficiently optimize the window performance without heavily relying on extensive measurement. Many researchers have presented simulation work on natural ventilation, for example, Evola et al. (2006), Flaga-Maryanczyk et al. (2014), and Stephen et al. (2014). Some of these studies include comparison and calibration with experimental measurements. A broad range of natural ventilation conditions have been investigated, spreading over different climate conditions and different types of buildings. For example, Ramponi et al. (2012) systematically investigated the sensitivity of computational parameters to be defined in the CFD simulation. Aflaki et al. (2015) reviewed many passive design strategies for natural ventilation in tropical climates. Li et al. (2015) proposed a method to predict the natural ventilation potential for residential buildings in cold climate region. Particularly for high-rise buildings, Sivakumar et al. (2010) found that changing the pressure distribution around the building envelope and the size of ventilation ports were two effective methods for controlling the air distribution within the building. Zhou et al. (2014) discussed the method to improve natural ventilation with unfavourably low wind speed through design optimization. The main advantages of developing simulation models are that CFD results provide a clear picture of the flow and thermal fields, and the parametric effect of relevant design variables can be systematically investigated.

There exist a number of quantitative models for describing thermal comfort responses under natural ventilation condition. The most widely used Predicted Mean Vote (PMV) model was proposed by Fanger (1970), who mathematically calibrated the thermal comfort of indoor climate. For studies performed in Humid tropical climate, Busch (1992) conducted field experiment for naturally ventilated office in Thailand and suggested a temperature of $28.5^{\circ} \mathrm{C}$ as the thermal neutrality. de Dear et al. (1991) studied the thermal comfort in naturally ventilated buildings in Singapore on the seven-point scale, and concluded that a mean comfort vote of +0.66 (between 'just right' and 'slightly warm') was obtained from field experiment, with a mean temperature of $29.6{ }^{\circ} \mathrm{C}$, a mean relative humidity of $74 \%$ and a mean indoor air velocity of $0.22 \mathrm{~m} / \mathrm{s}$. Wong et al. (2002) continued to survey on the thermal perception in Singapore and examined the subjective assessment variation between three sessions of the day, building floor levels and flat types. Sekhar et al. (2011) further studied thermal comfort and indoor air quality (IAQ) of naturally/mechanically ventilated (NMV) and air-conditioned bedrooms, and found that NMV bedroom provides a better sleeping environment.

The application of natural ventilation is affected by many factors such as the outdoor climate, environmental noise and air pollution. To implement natural ventilation for residential buildings, the thermal comfort and the indoor noise level for occupants staying in the buildings are two important factors that should be considered simultaneously (De Salis et al. 2002, Barclay et al. 2012). As natural ventilation requires an open window, the combined sound insulation of the building façade is significantly deteriorated by the opening. Oldham et al. (1993) and Trompette et al. (2009) have shown that sound can easily transmit through an aperture with moderate size. If the acoustic comfort cannot be satisfied, people would tend to close the window and choose air-conditioning. Thus, to ensure a successful implementation of natural ventilation technology, the acoustic performance of the adopted window design needs to be optimised.

Many researchers attempted to develop ventilation window with enhanced noise mitigation performance. Ford et al. (1973) first proposed partially open double glazing with staggered inlet-outlet opening, which was later extended by Kang et al. (2005) to include microperforated panel absorber; by Huang et al. (2011) to incorporate active noise cancellation 
technique; and by Søndergaard et al. (2012) to add porous absorbing material. De Salis et al. (2002) reviewed a number of noise control techniques that could reduce the road traffic noise of a façade incorporating ventilation openings. The advantages and disadvantages of passive, active and hybrid control techniques were discussed. Barclay et al. (2012) examined the traffic noise level in urban environment and proposed an integrated approach for combining noise exposure and ventilation performance together. More recently, Yu et al. (2017) developed the numerical model to predict the Sound Reduction Index (SRI) of ventilation windows, and discussed the potential of using simulation tool to optimize the parameters involved in the system design. Tang (2017) reviewed the research and development of natural ventilationenabling noise control devices and suggested that plenum windows with a staggered air inletoutlet can be used as building façades in the tropical and sub-tropical climatic regions. However, although specific investigations on flow or acoustic aspects of naturally ventilated buildings have been extensively performed, more sophisticated analysis with combined investigations and analyses has been rather limited.

The aim of this research is therefore to develop a suitable ventilation model in addition to the acoustic model (Yu et al. 2017), to systematically assess the integrated ventilation and acoustic performance of ventilation window. In particular, a case study is presented by looking into the high-rise public housing in hot and humid environment in Singapore, which is challenging but less explored in the literature. CFD model for simulating natural ventilation is developed for a generic isolated building. Under certain airflow condition, the distribution of air velocity and temperature field inside a representative residential unit is calculated. The thermal comfort is then evaluated using a statistical model based on the Predicted Mean Vote (PMV) method. As for the acoustic simulation, the window noise mitigation described by the SRI is predicted using Finite Element Method (FEM). To predict the indoor noise level, noise radiation from road traffic is assumed as the noise source, and the noise exposure to the building façade is combined with the façade sound insulation. For the overall performance of the ventilation window, the integrated thermal and acoustical performance are analysed together. Based on the temperature variation in Singapore during day/night-time and in different seasons, the thermal comfort is discussed according to the simulation results with different window opening size. The noise exposure as a result of the ventilation opening is also investigated.

\section{Methodology}

\subsection{The window system and the computational configurations}

This study investigates into the thermal and acoustic response in high-rise residential building which employs double-layer noise mitigation window for natural ventilation (Yu et al. 2017). The window structure is schematically shown in Fig. 1(a), which consists of two window layers that are partially opened and staggered. The inlet and outlet openings and the air duct between the two layers form an S-shaped airflow path denoted by the green arrow in Fig. 1(b). The window can be adjusted to a certain opening size to control the passage of airflow. An opening ratio $O$ is defined as the window opening area over the whole surface area. To address the effect of varying opening size on the ventilation and acoustic performance, three opening ratios $O_{1}=1 / 2, O_{2}=1 / 3$ and $O_{3}=1 / 6$ are tested in the simulation. The open ratio for the first and second window layer is kept the same for the sake of simplicity. 
(a)

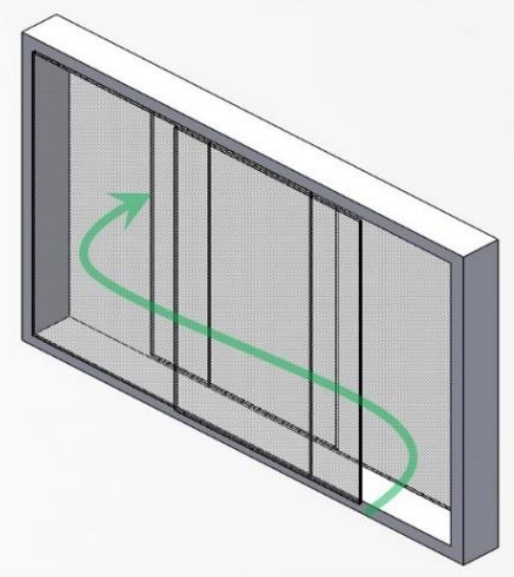

(b)

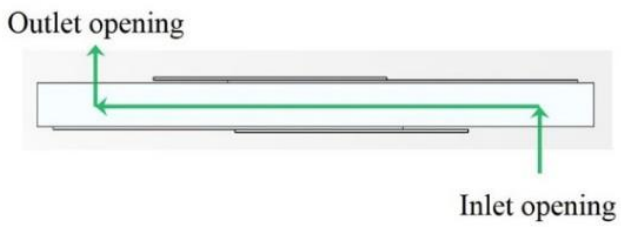

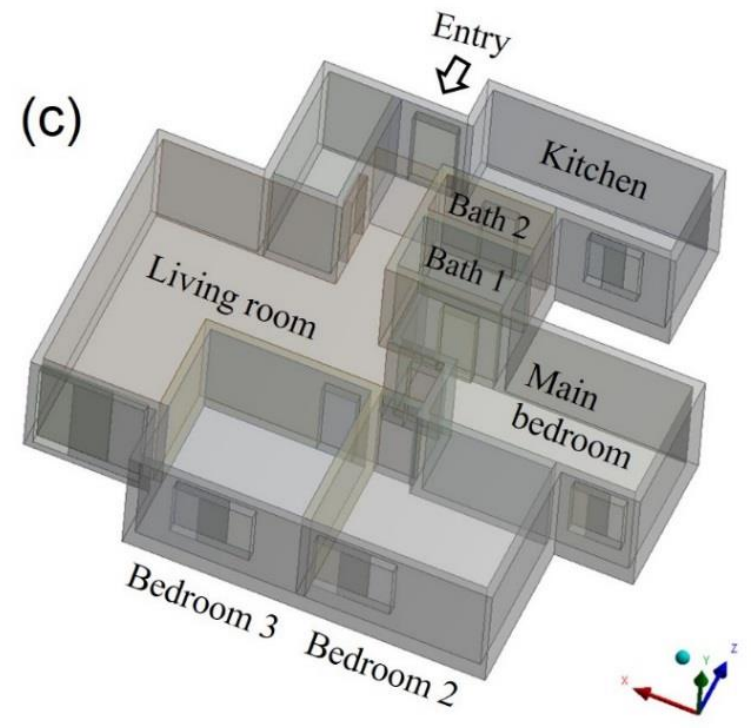

Fig. 1. (a) Schematic of a double-layer ventilation window; (b) the S-shaped ventilation path formed by the inlet-outlet opening and the air duct; (c) three-dimensional unit configuration.

The geometry of the simulation unit stems from the floor plan of a Singapore public housing is sketched in Fig. 1(c). The unit consists of a living room, three bedrooms, a kitchen, two toilets and a storage room. $x$-, $y$-, and $z$ - axes are used to denote the lateral, height and depth dimension of the unit. The total dimension of the unit is $12.9 \mathrm{~m}(x) \times 3 \mathrm{~m}(y) \times 12.2 \mathrm{~m}(z)$. The room spaces are separated by partition walls with six doors, and a main door as the entry. All the doors are assumed as fully opened in the simulation. The unit employs five ventilation windows in the living room, three bedrooms and the kitchen, whose corresponding window dimensions are listed in Table 1. All the windows are adjusted to one specific opening ratio to reduce the total number of cases.

Table. 1. Dimensions of the five ventilation windows.

\begin{tabular}{|l|c|c|c|c|c|}
\hline & Living room & Bedroom 2 & Bedroom 3 & Master bedroom & Kitchen \\
\hline Height $(\mathrm{m})$ & 2.5 & 1.5 & 1.5 & 1.5 & 1.5 \\
\hline Width $(\mathrm{m})$ & 2.4 & 1.8 & 1.8 & 1.2 & 1.2 \\
\hline
\end{tabular}

An isolated, high-rise building is considered, which neglects the flow interaction with the surrounding buildings. The whole building except for the unit to be simulated is simplified as a concrete block, and the unit is located in the centre of the block in the lateral direction, as shown in Fig. 2(a). Two more adjacent units are assumed on both sides of the unit, giving a total lateral width of $W=64.5 \mathrm{~m}$ for the building block. The high-rise building is assumed to have 25 floors with a total height of $H=75 \mathrm{~m}$. The dimension of the whole building block is therefore $64.5 \mathrm{~m}(x) \times 75 \mathrm{~m}(y) \times 12.2 \mathrm{~m}(z)$. To account for the effect of building floor levels, three positions at $4^{\text {th }}$ (low), $13^{\text {th }}$ (middle) and $22^{\text {nd }}$ (high) floors are chosen, where the centre of each position is at the height of $H_{1}=10.5 \mathrm{~m}, H_{2}=37.5 \mathrm{~m}$ and $H_{3}=64.5 \mathrm{~m}$, respectively. In 
the following two sub-sections, the CFD model to predict the thermal response inside the unit, and the FEM model to characterize the building façade sound insulation will be detailed.
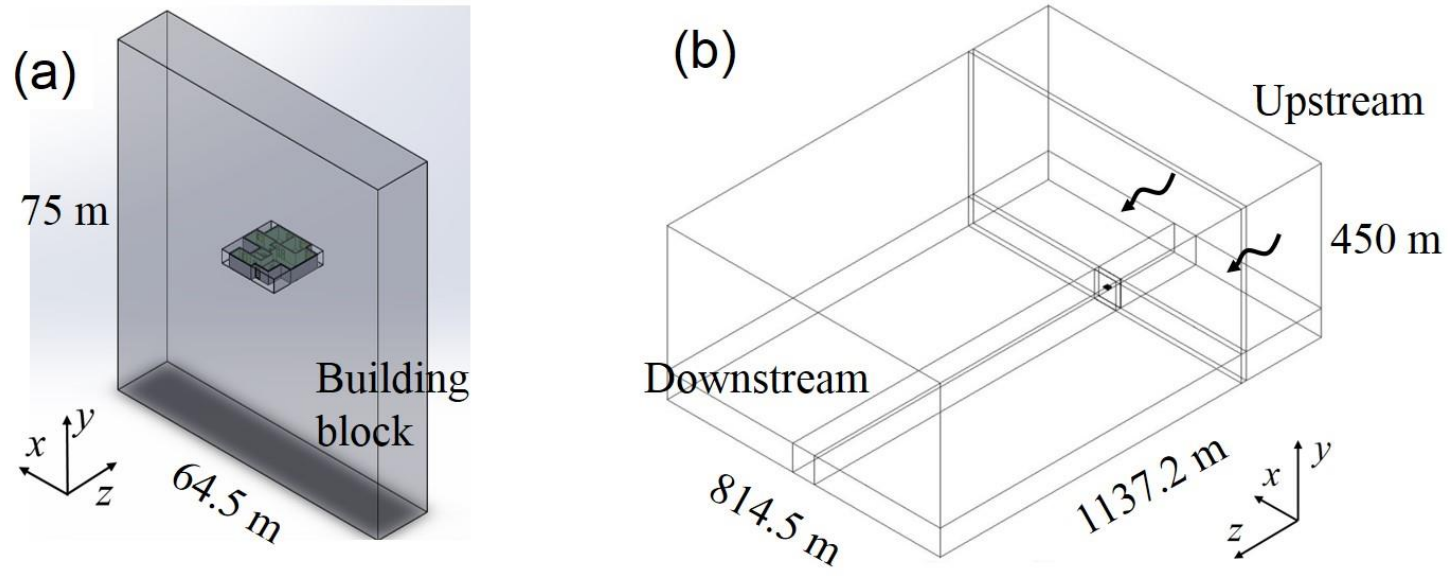

Fig. 2. (a) Simulation unit in the building block located in the middle level. (b) Definition of

the CFD computational domain.

\subsection{CFD ventilation simulation}

The ventilation performance of the window configuration and the assessment of thermal comfort highly depend on the outdoor wind flow condition. This study limits the outdoor climate to the hot tropical environment. The daily temperature in Singapore ranges from an averaged minimum of $24{ }^{\circ} \mathrm{C}$ and a maximum of $31{ }^{\circ} \mathrm{C}$, and the annual mean temperature is $26.6^{\circ} \mathrm{C}$ (Wong et al. 2002). The ventilation analysis is carried out using coupled CFD approach, which solves the building exterior and interior flow field together (Ramponi et al. 2012).

The CFD model is developed using commercial software Fluent. According to the best practice guidelines by Franke (2007), the dimension of the computational domain is chosen with respect to the building height $H$. Five more building heights $5 H$ is used above the building top and on both sides of the building block to avoid interference with the result. The upstream and downstream length of the computation domain is set as $3 H$ and $12 H$ (Tominaga et al. 2008). The dimension of the whole computational domain, as shown in Fig. 2(b), is $814.5 \mathrm{~m}(x) \times 450$ $\mathrm{m}(y) \times 1137.2 \mathrm{~m}(z)$. The inlet boundary condition at $Z=0 \mathrm{~m}$ is assigned with a mean wind speed $V_{0}$ and an initial temperature $T_{0}$. To account for the wind speed variation at different levels, the vertical wind profile governed by the power law is (Feustel 1999):

$$
V(z)=V_{\text {ref }}\left(z / z_{\text {ref }}\right)^{\alpha}
$$

where $z_{\text {ref }}$ is the reference height, $V_{\text {ref }}$ is the wind velocity at the reference height, $\alpha$ is the empirical power law exponent taken as 0.4 for city areas. Based on the wind data measured in Singapore for the past 18 years (BCA 2015), the mean wind velocity at a reference height of $z_{\text {ref }}=15 \mathrm{~m}$ is $2.0 \mathrm{~m} / \mathrm{s}$ and $2.9 \mathrm{~m} / \mathrm{s}$ in the North and North-east wind directions, and $2.8 \mathrm{~m} / \mathrm{s}$ and $3.2 \mathrm{~m} / \mathrm{s}$ in the South and South-East condition. Since the simulation only considers an isolated building, the smallest value $V_{r e f}=2.0 \mathrm{~m} / \mathrm{s}$ is taken as the reference speed to compromise the possible effect of flow interactions between buildings. 
According to the above formula, the inlet wind speeds calculated at the low $\left(H_{1}=10.5\right.$ $\mathrm{m})$, middle $\left(H_{2}=37.5 \mathrm{~m}\right)$ and high floors $\left(H_{3}=64.5 \mathrm{~m}\right)$ are $V_{1}=1.7 \mathrm{~m} / \mathrm{s}, V_{2}=2.9 \mathrm{~m} / \mathrm{s}$ and $V_{3}$ $=3.6 \mathrm{~m} / \mathrm{s}$, respectively. To account for the effect of wind incident angle, three more wind speeds at $45^{\circ}$ incident angle is included, where $V_{4}=1.2 \mathrm{~m} / \mathrm{s}, V_{5}=2.0 \mathrm{~m} / \mathrm{s}$ and $V_{6}=2.5 \mathrm{~m} / \mathrm{s}$ at the three floor positions. In addition to that, one more low wind speed condition is taken as $V_{7}=$ $0.5 \mathrm{~m} / \mathrm{s}$. Therefore, the wind speed range considered in the simulation is from $0.5 \mathrm{~m} / \mathrm{s}$ to 3.6 $\mathrm{m} / \mathrm{s}$. As for the inlet air temperature, three typical temperature values are chosen as $T_{1}=25^{\circ} \mathrm{C}$, $T_{2}=27^{\circ} \mathrm{C}$ and $T_{3}=30^{\circ} \mathrm{C}$. The initial temperature for the walls in the unit is set as $T_{\text {wall }}=30^{\circ} \mathrm{C}$. The simulation conditions including the window opening ratio $O$, outdoor wind flow speed $V$ and temperature $T$ are summarized in Table 2.

Table. 2. List of window opening ratios and outdoor wind flow parameters considered in the simulation.

\begin{tabular}{|l|l|l|}
\hline Window opening ratio & Inlet wind speed $V$ (smallest to largest) & Inlet wind temperature \\
\hline$O_{1}=1 / 2$ & $V_{7}=0.5 \mathrm{~m} / \mathrm{s}$ (low wind speed) & $T_{1}=25^{\circ} \mathrm{C}$ \\
$O_{2}=1 / 3$ & $V_{4}=1.2 \mathrm{~m} / \mathrm{s}$ (low level, $\left.45^{\circ}\right)$ & $T_{2}=27{ }^{\circ} \mathrm{C}$ \\
$O_{3}=1 / 6$ & $V_{1}=1.7 \mathrm{~m} / \mathrm{s}$ (low level, normal) & $T_{3}=30^{\circ} \mathrm{C}$ \\
& $V_{5}=2.0 \mathrm{~m} / \mathrm{s}$ (Middle, $\left.45^{\circ}\right)$ & \\
& $V_{6}=2.5 \mathrm{~m} / \mathrm{s}$ (High level, $\left.45^{\circ}\right)$ & \\
& $V_{2}=2.9 \mathrm{~m} / \mathrm{s}$ (Middle level, normal) & \\
& $V_{3}=3.6 \mathrm{~m} / \mathrm{s}$ (High level, normal) & \\
&
\end{tabular}

At the downstream outlet plane where $Z=1137.2 \mathrm{~m}$, pressure release condition is applied with $P=0$. The ground surface at $Y=0 \mathrm{~m}$ is defined as a hard wall and symmetric conditions are applied to the top and lateral planes of the computational domain. The general mesh requirement for the unit space of interest is between $0.1 \mathrm{~m}$ to $0.5 \mathrm{~m}$, which is loosened to between $1 \mathrm{~m}$ and $5 \mathrm{~m}$ for the space surrounding the building. The total number of elements for discretizing the CFD domain was about 11.3 millions. The commonly used standard $k-\varepsilon$ turbulent model was employed in the simulations (Buratti et al. 2011). The SIMPLE algorithm was used for pressure-velocity coupling. The second-order discretization scheme was used for pressure, and second order upwind scheme for momentum, $k, \varepsilon$ and energy. Convergence criteria were set as that all the scaled residuals were less than $10^{-3}$ for continuity, $x, y$ and $z$ velocities, $k$ and the residual of energy is less than $10^{-6}$.

To quantitatively evaluate thermal comfort, the interior airflow field and temperature distribution is simulated under a specific inlet wind condition. The thermal comfort index using the PMV method is calculated as (Fanger 1970):

$$
\begin{aligned}
& \mathrm{PMV}=\left(0.303 e^{-0.036 M}+0.028\right)\left\{(M-W)-3.96 \times 10^{-8} f_{c l}\left[\left(T_{c l}+273\right)^{4}-\left(T_{r}+273\right)^{4}\right]\right. \\
& \quad-f_{c l} h_{c}\left(T_{c l}-T_{a}\right)-3.05 \times 10^{-3}\left[5733-6.99(M-W)-P_{a}\right]-0.42[(M-W)-58.15] \\
& \left.\quad-0.0014 M\left(34-T_{a}\right)-1.7 \times 10^{-5} M\left(5876-P_{a}\right)\right\}
\end{aligned}
$$


where $M$ is the metabolic rate, $M=70 \mathrm{~W} / \mathrm{m}^{2} . W$ is the external work, assumed as $W=0 \mathrm{~W} / \mathrm{m}^{2}$ for people seating without activity. $f_{\mathrm{cl}}$ is the clothing factor describing heat insulation condition of the clothes. $h_{c}$ is the convective heat transfer coefficient, $h_{c}=12.1(V)^{1 / 2}$, with $V$ being the air velocity in $\mathrm{m} / \mathrm{s} . T_{\mathrm{a}}$ is the air temperature at the evaluation point, $T_{\mathrm{r}}$ is the mean radiant temperature, and $T_{\mathrm{cl}}$ is the clothing surface temperature, all in ${ }^{\circ} \mathrm{C} . P_{\mathrm{a}}$ is the water vapour partial pressure, calculated from the relative humidity $(\mathrm{RH})$ at different air temperature. The $\mathrm{RH}$ in Singapore is taken as $80 \%$ in average. The PMV calculated using the above formula on the seven-point scale is interpreted as: hot $=+3$; warm $=+2$; slightly warm $=+1$; neutral $=0$; slightly cool $=-1$; cool $=-2$; cold $=-3$.

By post-processing the air velocity and temperature data from CFD simulation, the thermal scale at every point inside the unit can be calculated. The recommended acceptable range for thermal comfort is between -1 and +1 , corresponding to 'slightly cool' and 'slightly hot' scale. As CFD simulation produces the entire flow and temperature field data, the PMV profile at any horizontal plane can be evaluated. A fixed height of $1.1 \mathrm{~m}$ above the floor is taken as the plane for thermal comfort analysis. The percentage of satisfaction is defined as the percentage of area (in the plane of interest) with PMV lies in the comfortable range, which will be used later to compare the ventilation performance with respect to different parameters.

\subsection{FEM acoustic simulation}

Further to the ventilation simulation, acoustic performance of the ventilation window is simulated. As road traffic constitutes the major noise sources in Singapore, a simple traffic source is assumed to demonstrate the calculation of indoor noise level from the façade noise exposure and façade attenuation. In the following steps, the empirical Calculation of Road Traffic Noise (CRTN) model is first used to calculate the façade noise level given a traffic condition and a distance between the road and receiver (C. M. Mak 2010). The façade SRI is determined by employing Finite Element Method (FEM) simulation for air-borne sound transmission. The indoor noise level is then obtained by combining the noise exposure, façade insulation and room absorption correction.

The traffic noise model assumed as the building noise exposure is illustrated in Fig. 3, where the residential building with 25 floors is located near a straight road. For the sake of simplicity, the noise barrier, opposite façade and road gradient effect are neglected. The classical CRTN model to predict the Basic Noise Level (BNL) at the road edge is:

$$
L_{B N L}=10 \log Q+33 \log (V+40+500 / V)+10 \log (1+5 P / V)+0.3 G-26.6
$$

where $Q$ is the vehicle flow rate. $V$ is the vehicle speed. $P$ is the percentage of heavy vehicle. $G$ is the road gradient.

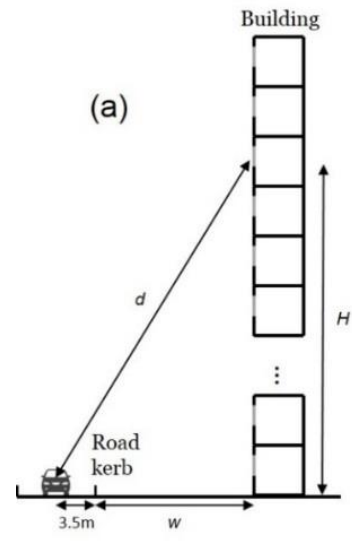

(b)

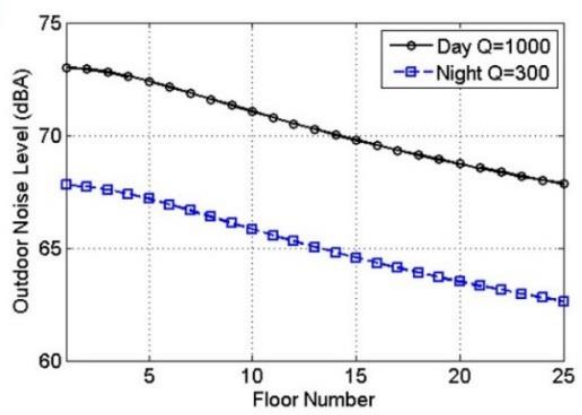


Fig. 3. (a) Traffic model for building noise exposure; (b) Outdoor noise level versus floor number predicted using CRTN model, during day-time and night-time.

The noise level reaching the façade side of the building, at each floor, can be calculated using the distance correction term given by $-10 \log (d / 13.5)$. The distance $d$ from the receiver to the noise source is:

$$
d=\sqrt{(w+3.5)^{2}+H^{2}}
$$

where $w$ is the horizontal distance between the building and the road. $H$ is the height of the receiving unit. By assuming $w=20 \mathrm{~m}, V=50 \mathrm{~km} / \mathrm{h}, P=30 \%$ and a mean floor height of $3 \mathrm{~m}$, Fig. 3(b) shows the variation of outdoor noise level versus the building height. Two traffic flow conditions are assumed for different session of the day. During day-time, the traffic flow is assumed as $Q=1000$ per hour, and the noise exposure varies from 68 to $73 \mathrm{dBA}$. During nighttime, the traffic flow is reduced to $Q=300$ per hour, and the noise exposure reduces to 62 - 68 $\mathrm{dBA}$. The noise level received at different building floors has 5 to $6 \mathrm{dBA}$ difference from top to bottom positions.

The sound insulation performance of ventilation window is simulated using acoustic FEM model (Yu et al. 2017). The ventilation window is placed between a source room and a receiving room, where the dimensions of the two rooms are depicted in Fig. 4. The SRI is defined as the ratio between transmitted sound energy and incident sound energy, calculated in the logarithmic scale. Three-dimensional FEM model was developed to simulate the airborne sound transmission through the ventilation window. The wall surfaces of the source and receiving room are rigid, representing diffuse room condition in experiment. The frequency sweep is defined as sixteen $1 / 3$ octave bands from $100 \mathrm{~Hz}$ to $3150 \mathrm{~Hz}$, with 30 frequency points in each band. The SRI results at discrete frequency points are averaged within each 1/3 octave band, and rated using ISO-717 to obtain the Single Number Quantity (SNQ) value (ISO7171:2013 2013). Due to the limit of computational power, the FEM mesh was generated using free-tetrahedral element according to one-eighth of the acoustic wavelength at $500 \mathrm{~Hz}$, as shown in Fig. 4(b). The system has two millions degrees of freedom and require about 130 hours CPU time to solve (on workstation with Intel E5-2650 v2 CPU and 128 GB memory).
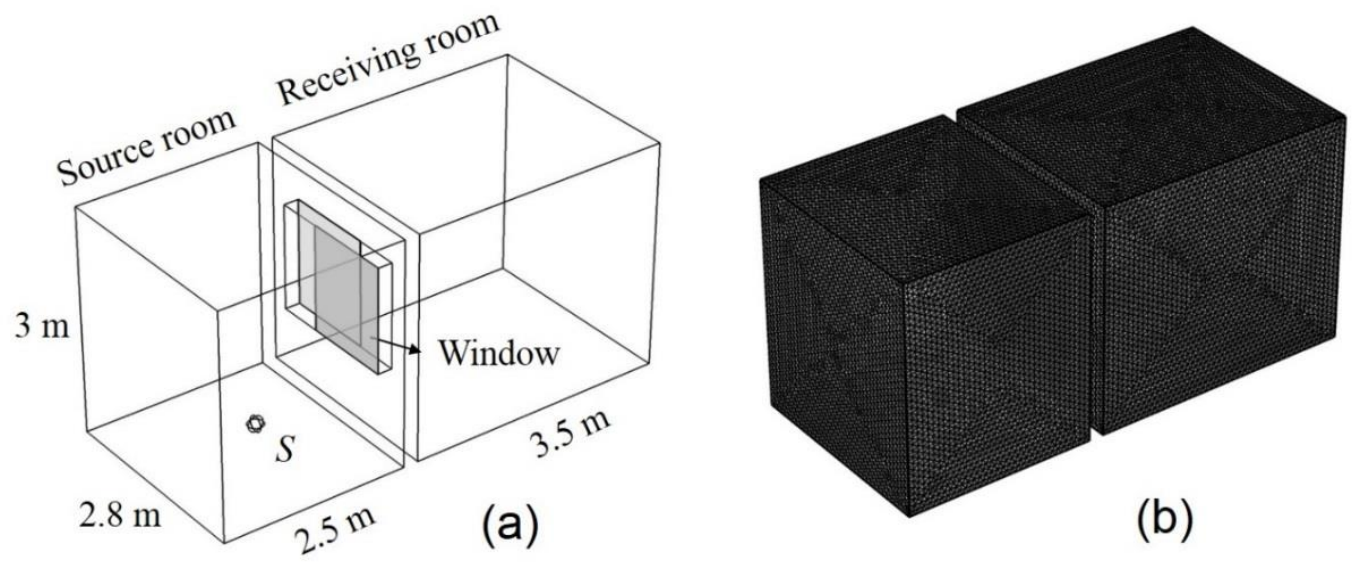

Fig. 4. (a) Three-dimensional FEM model for acoustic simulation of window SRI; (b) FEM mesh generated using free-tetrahedral element. 
Since ventilation window presents openings, its sound insulation is weaker compared with the relatively hard building wall. The combined sound insulation provided by the building façade, namely the building wall with the ventilation window, can be calculated as:

$$
R=-10 \log \left(\frac{S_{r} \times 10^{-\frac{\mathrm{SRI}_{r}}{10}}+S_{v} \times 10^{-\frac{\mathrm{SRI}_{v}}{10}}}{S_{r}+S_{v}}\right)
$$

where $r$ denotes the relatively rigid building wall, $v$ denotes the ventilation window. $S_{r}$ and $S_{\mathrm{v}}$ are their corresponding area, $\mathrm{SRI}_{r}$ and $\mathrm{SRI}_{v}$ are the sound reduction indices of the wall and the window, respectively.

The indoor noise level $L_{\text {in }}$ can be estimated by:

$$
L_{\text {in }}=L_{\text {out }}-R+C_{\text {room }}
$$

where $L_{\text {out }}$ is the outdoor noise level reaching the façade of the building, as assumed in Fig. 4(b) . $C_{\text {room }}$ is the room correction factor related to the room size and room absorption, which can be determined by the measured reverberation time in practice. $C_{\text {room }}$ is assumed as $2.4 \mathrm{~dB}$ for general room condition according to Barclay et al. (2012).

\section{Results}

\subsection{Thermal comfort}

As described in Sec. 2.2, the indoor flow and temperature field under a prescribed outdoor wind condition is solved by coupled CFD simulation. For illustration, with inlet wind speed $V_{0}=1.2 \mathrm{~m} / \mathrm{s}$ and temperature $T_{0}=25{ }^{\circ} \mathrm{C}$, the air velocity and temperature distribution at a height of $1.1 \mathrm{~m}$ above the floor are shown in Fig. 5(a) \& (b). The window opening ratio is $O=1 / 6$. It is observed that the dominant airflow passage is from the ventilation window in the living room to the entrance door, as it has the largest opening connected to downstream flow domain. Also airflow pattern which enters from the ventilation windows in the three bedrooms, penetrates through the interior doors and escapes from the kitchen window can be seen. The indoor air velocity is between $0 \mathrm{~m} / \mathrm{s}$ and $0.8 \mathrm{~m} / \mathrm{s}$, with a mean of $0.1 \mathrm{~m} / \mathrm{s}$. The flow rate describing the fresh air volume flowing into the unit per unit time was checked, which satisfies the fresh air requirement for naturally ventilated building (ASHRAE 2007). Since the temperature of incoming flow is lower than the initial wall setting, the indoor air is cooled down by the ventilation. The average temperature over the whole unit is $28.5^{\circ} \mathrm{C}$. The thermal vote calculated using classical PMV formula is shown in Fig. 5(c), where majority of room area lies in between -1 (slightly cool) and +1 (slightly warm) range. The area coloured in blue marks the air passage where the air velocity is higher and the temperature is lower. The PMV in the blue area is lower than -1 which denotes the overcooled region. The temperature in the two small toilets next to the master bedroom and the kitchen remain high due to lack of sufficient ventilation, and the thermal response with PMV greater than +1 shows the region is hot. By defining the satisfaction as the percentage of comfortable area (with PMV between -1 and +1 ) over the whole unit area, overall $70 \%$ of area shows satisfaction response with $V_{0}=1.2$ $\mathrm{m} / \mathrm{s}, T_{0}=25{ }^{\circ} \mathrm{C}$ and $O=1 / 6$. 
(a)

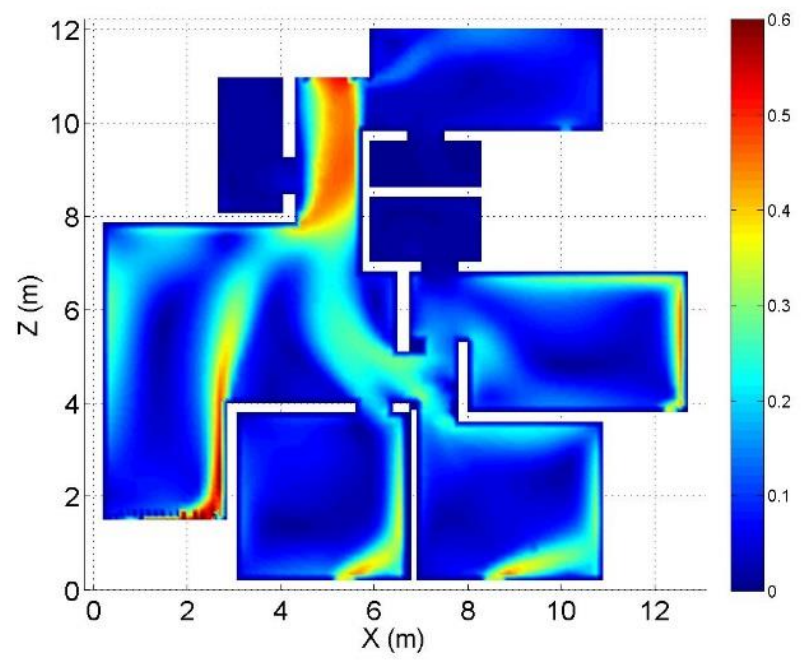

(b)

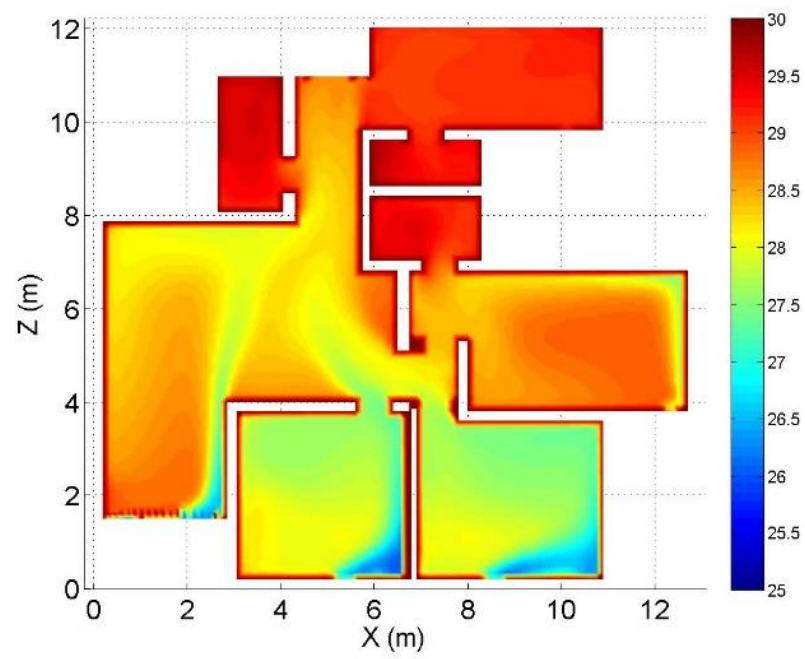

(c)

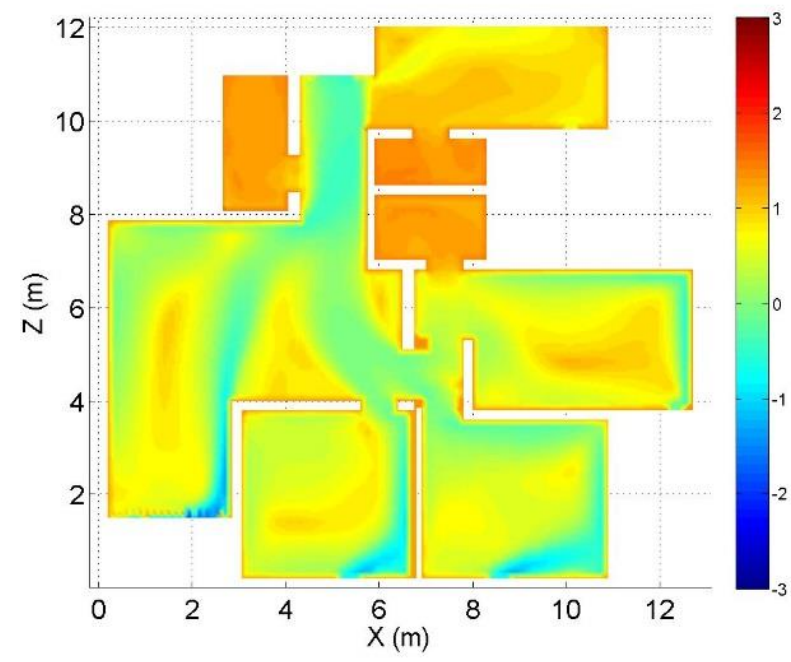


Fig. 5. CFD result with inlet wind speed $V_{0}=1.2 \mathrm{~m} / \mathrm{s}$ and temperature $T_{0}=25{ }^{\circ} \mathrm{C}$ : (a) indoor air velocity profile, in $\mathrm{m} / \mathrm{s}$; (b) indoor air temperature distribution, in ${ }^{\circ} \mathrm{C}$; (c) PMV profile. All taken at a horizontal plane $1.1 \mathrm{~m}$ above the floor.

With inlet air temperature being kept at $T_{0}=25^{\circ} \mathrm{C}$, the effect of varying wind speed $V_{0}$ and window opening ratio $O$ on the thermal response is studied. Fig. 6(a) shows the percentage of area with satisfied PMV versus inlet wind speed, where the three curves depicted the three opening ratios. It is observed that the satisfaction percentage increases from $V_{0}=0.5$ $\mathrm{m} / \mathrm{s}$ and reaches the maximum at $V_{0}=1.2 \mathrm{~m} / \mathrm{s}$. The best thermal vote is obtained with $V_{0}=1.2$ $\mathrm{m} / \mathrm{s}$ and window opening ratio $O=1 / 6$, where $70 \%$ of the unit area is considered as comfortable for the occupants. After that, the satisfaction rate gradually decreases with the increase of inlet wind speed, and such decrease is more rapid with larger window opening. To explain this, the percentage of room area with PMV below -1.0 scale ('slightly cool') is presented in Fig. 6(b). The results indicate that people start to feel cold in larger region with increasing inlet wind speed, which causes the thermal vote to deteriorate. In that case smaller window opening helps to reduce the cold area and maintain a satisfactory thermal condition. Overall speaking, CFD simulation suggests that comfortable indoor climate can be achieved with natural ventilation when the outdoor wind temperature is at $25^{\circ} \mathrm{C}$.

(a)
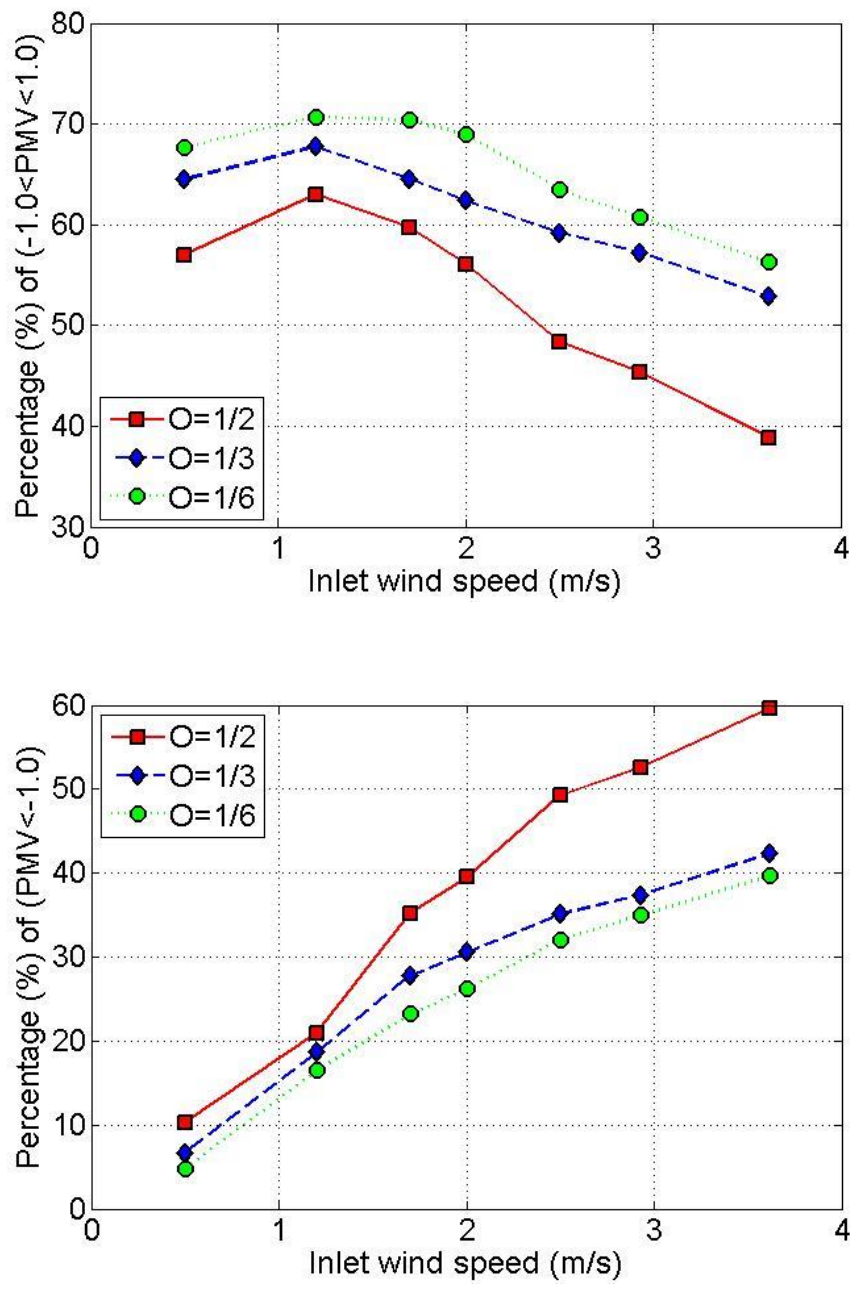
Fig. 6. (a) Effect of varying inlet wind speed $V_{0}$ and window opening ratio $O$ on the percentage of room area with satisfied PMV; (b) Percentage of room area with PMV below -

$$
1.0 \text { ('slightly cool'). }
$$

In Fig. 7 (a) (c), the CFD results for the three inlet temperature $T_{1}=25^{\circ} \mathrm{C}, T_{2}=27{ }^{\circ} \mathrm{C}$, and $T_{3}=30{ }^{\circ} \mathrm{C}$ are compared. The range for inlet wind speed range is narrowed to $0.5 \mathrm{~m} / \mathrm{s}$ to $2.6 \mathrm{~m} / \mathrm{s}$. It is observed that with higher temperature, the thermal vote is worse especially when incoming wind speed is low. As the inlet wind speed increases, the indoor thermal comfort improves, and generally the improvement is more rapid with larger window opening. The optimal thermal vote can be obtained either with $T_{0}=25^{\circ} \mathrm{C}, V_{0}=1.2 \mathrm{~m} / \mathrm{s}, O=1 / 6$, or with $T_{0}$ $=27{ }^{\circ} \mathrm{C}, V_{0}=1.7 \mathrm{~m} / \mathrm{s}, O=1 / 2$, showing the possible compensation between temperature and airflow. Generally, with $T_{0}=25^{\circ} \mathrm{C}$, more than half of the room space has acceptable PMV, and the window opening size can be reduced to avoid overcooling. With $2{ }^{\circ} \mathrm{C}$ warmer $T_{0}=27{ }^{\circ} \mathrm{C}$, thermal comfort can be maintained with sufficient window opening size to ensure enough indoor airflow. The ventilation performance starts to drop with smaller window opening, especially under low incoming wind speed. The result for $T_{3}=30^{\circ} \mathrm{C}$ shows a similar behaviour, but due to high temperature, to obtain an acceptable PMV becomes more difficult compared to the previous two cases. The PMV shows a consistent increasing trend with higher wind speed, i.e., higher indoor air velocity. But overall the satisfaction area percentage is low unless the outdoor environment is very windy. It should be reminded that the present study only focuses on natural ventilation. One can expect that thermal response will improve if natural/mechanical combined ventilation (such as fans) is adopted, mainly by enhancing the indoor air circulation.

(a)

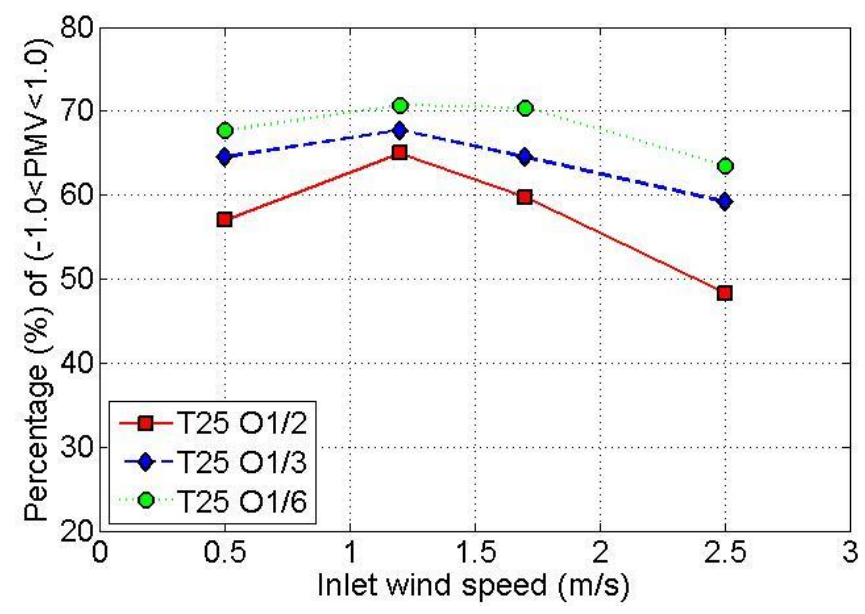


(b)

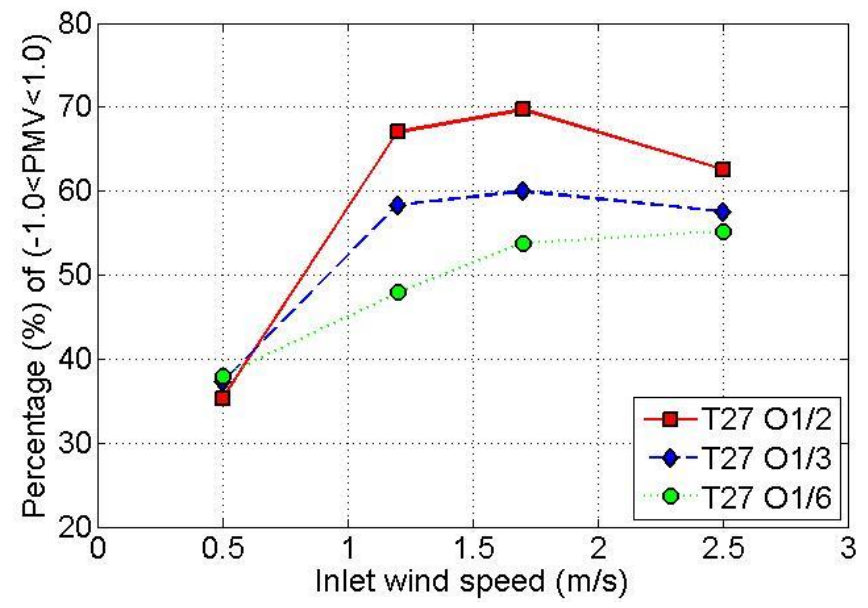

(c)

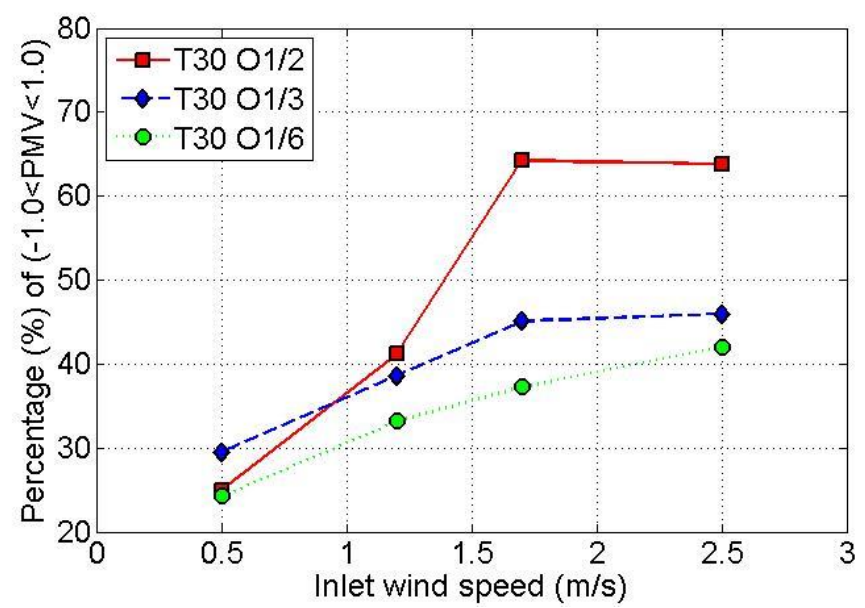

Fig. 7. Thermal response (percentage of room area with acceptable PMV) versus inlet wind speed and window opening ratio. The air temperature is : a) $T_{1}=25^{\circ} \mathrm{C}$; b) $T_{2}=27{ }^{\circ} \mathrm{C}$; c) $T_{3}$

$$
=30^{\circ} \mathrm{C} \text {. }
$$

\subsection{Acoustic comfort}

The sound field inside the source and receiving room from FEM simulation are processed to calculate the SRI of the ventilation window. Figure 8(a) shows a typical simulation result with window opening ratio $O=1 / 2$, where the source room and receiving room Sound Pressure Level (SPL) refers to the spatially averaged SPL over the respective room volume. The source and receiver SPL at the discrete frequency points is then averaged in each $1 / 3$ octave band, and subtracted to obtain the SRI curve. The SRI is presented in the $1 / 3$ octave frequency range from $100 \mathrm{~Hz}$ to $3150 \mathrm{~Hz}$ (red solid line with square maker), and ISO-717 is applied to calculate the ventilation window SNQ for airborne sound insulation, as indicated by the black dashed rating curve. 

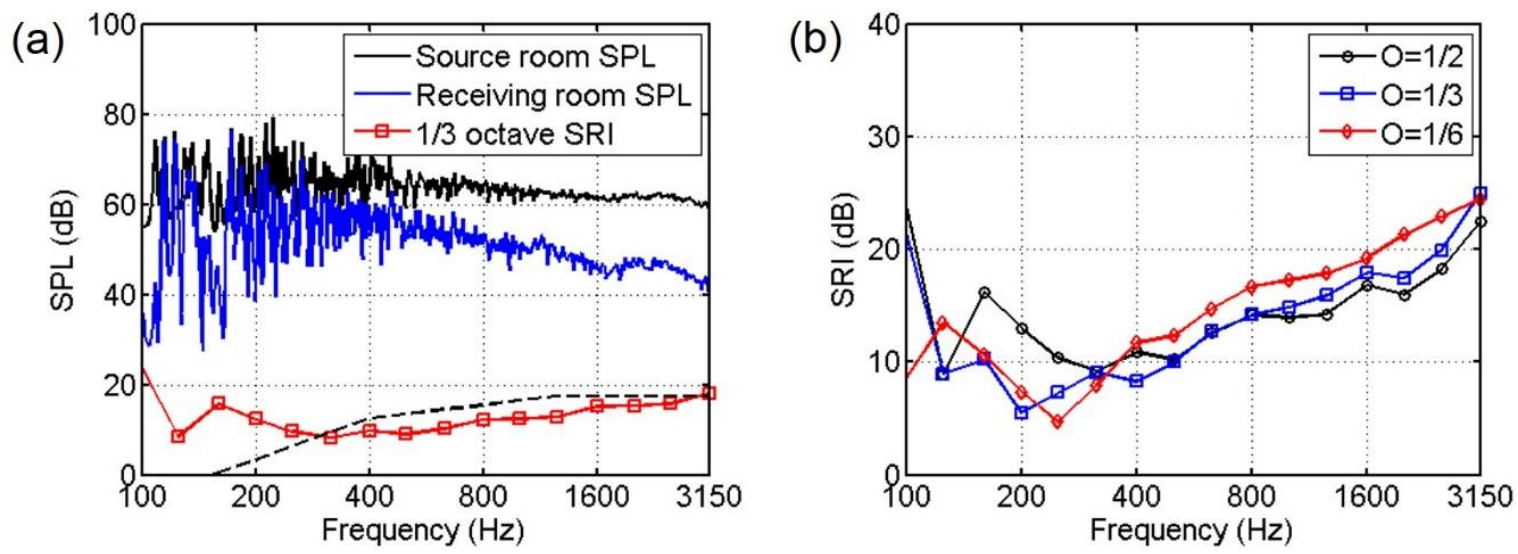

Fig. 8. (a) FEM simulation result for sound insulation of ventilation window, opening ratio

$O=1 / 2$; (b) Comparison of $1 / 3$ octave band SRI results for different window opening ratio.

The predicted SRIs for the three opening sizes are presented in Fig. 8(b) from $100 \mathrm{~Hz}$ to $3150 \mathrm{~Hz}$. It is found that for frequencies higher than $400 \mathrm{~Hz}$, smaller opening size leads to better sound insulation. The increment by narrowing the opening from $1 / 2$ to $1 / 6$ is generally 3 to $5 \mathrm{~dB}$. At lower frequencies, the trend is reversed, possibly due to the diffraction effect which is more significant with smaller aperture size. The low frequency performance between $100 \mathrm{~Hz}$ and $400 \mathrm{~Hz}$ is rather weak, with SRI around $10 \mathrm{~dB}$. The predicted SRI curves are generally in good agreement with the measured result as reported by Søndergaard et al. (2012).

Table 3. Single Number Quantity (SNQ) for the predicted SRI results.

\begin{tabular}{|c|c|c|c|}
\hline Opening ratio & $R_{\mathrm{w}}$ & $R_{\mathrm{w}}+C$ & $R_{\mathrm{w}}+C_{\mathrm{tr}}$ \\
\hline $1 / 2$ & 15.1 & 14 & 13 \\
\hline $1 / 3$ & 15.3 & 14 & 13 \\
\hline $1 / 6$ & 16.7 & 16 & 14 \\
\hline
\end{tabular}

The SNQ for the predicted SRI results, weighted by ISO-717, is summarized in Table 3. $C$ and $C_{\text {tr }}$ are the adaptation terms for pink and urban traffic noises, respectively. As traffic noise source is assumed in Sec. 2.3, $R_{\mathrm{w}}+C_{\text {tr }}$ is used to describe the sound insulation. The ventilation window with three opening ratios has nearly the same SNQ of about 13-14 dB, although the $1 / 3$ octave SRI curves show some variation.

According to the geometry of the selected residential unit, the area ratio between window and building wall (for the façade facing to noise) $S_{\mathrm{v}} / S_{\mathrm{w}}$ is around $1 / 3$. Assuming the building wall is relatively rigid with $\mathrm{SRI}_{r}=40 \mathrm{~dB}$, the combined façade insulation with the ventilation window is 19-20 dB, which gives an indoor-outdoor level difference about $17 \mathrm{~dB}$ with the room correction factor $C_{\text {room }}$ being included. In the noise guideline by National Environment Agency of Singapore (Bin 2016), it is required that the indoor noise level shall not exceed $57 \mathrm{dBA}$ if the façade noise exposure is $67 \mathrm{dBA}$, which means that a $10 \mathrm{~dB}$ noise reduction must be fulfilled under natural ventilated condition. The façade SRI with the open ventilation window is around $20 \mathrm{~dB}$, which is much higher than the $10 \mathrm{~dB}$ requirement.

By combining the noise exposure, façade insulation and room correction together, the interior noise level in the residential unit can be calculated using Eq. (5). During the day-time when the façade noise exposure is $68-73 \mathrm{dBA}$, the indoor noise level is around 51-56 dBA. 
With less vehicle at night, the indoor noise level is reduced to 45-51 dBA with an outdoor noise level of 62-68 dBA. Generally, the noise guideline (Bin 2016) requires an indoor noise level below $65 \mathrm{dBA}$ in the day and below $55 \mathrm{dBA}$ at night. In such a case the ventilation window satisfies the noise guideline.

Particularly for sleeping comfort at night, noise guideline in EU recommended a lower limit of $40 \mathrm{dBA}$ for preventing sleep disturbance (Hurtley 2009). Studies showed that between $40 \mathrm{dBA}$ and $55 \mathrm{dBA}$, adverse health effects were observed among the population and people would have to adapt their lives to cope with noise at night. Based on these guidelines, the outside night noise exposure when using the ventilation window should not exceed $72 \mathrm{dBA}$. Ideally, the noise level should stay below $57 \mathrm{dBA}$ for undisturbed sleep. Apart from regulating the noise level from outside, further noise reduction can be made from the improvement of ventilation window. Studies have shown that adding absorbing material into the ventilation window (Søndergaard et al. 2012) and using acoustic meta-material design (Yu et al. 2017) can efficiently enhance the sound insulation performance. Using similar approach, new ventilation window designs can be considered in future studies.

\section{Overall performance of the ventilation window}

In this section, the thermal and acoustic analyses are combined together to assess the overall effectiveness of using ventilation window for high-rise buildings in Singapore. The climate in Singapore has a uniformly high temperature with a mean annual value of $26.6^{\circ} \mathrm{C}$, which is close to the simulation with $T_{0}=27^{\circ} \mathrm{C}$. CFD results in Fig. 7(b) indicate that thermal comfort at this temperature can be obtained with enough wind speed and window opening. In that case natural ventilation is more favourable at higher floors where the outdoor wind speed is higher, and the window needs to be adjusted to a sufficient opening ratio. The noise level at higher floors also decreases as an advantage, making natural ventilation more practical.

The temperature variation during the day and at night is not significant in Singapore. From the meteorological data (Singapore 2017), monthly summary statistics for the average temperature range in the four-hour interval are tabulated in Table 4. The hottest hours are usually from 12:00 to 16:00, and the coolest hours are from 4:00 to 8:00. During the day-time from 8:00 to 20:00, the mean temperature averaged over the twelve hours is about $28{ }^{\circ} \mathrm{C}$ to 29 ${ }^{\circ} \mathrm{C}$, and the mean night temperature $(20: 00$ to $8: 00)$ is from $25.5^{\circ} \mathrm{C}$ to $27.5^{\circ} \mathrm{C}$. It is also found that some months are slightly warmer than the other. From April to September, the mean temperature is $1{ }^{\circ} \mathrm{C}$ higher than the other months. To summarize, the relatively hot season including months from April to September has a mean temperature of $29{ }^{\circ} \mathrm{C}$ during the daytime, and $27^{\circ} \mathrm{C}$ during the night. In the relatively cool season from October to March, the mean temperature is $28{ }^{\circ} \mathrm{C}$ during the day, and $26^{\circ} \mathrm{C}$ at night.

Table 4. Singapore hourly temperature variation $\left({ }^{\circ} \mathrm{C}\right)$ across the year, data from 1982-2016.

\begin{tabular}{|c|c|c|c|c|c|c|c|}
\hline Hour & Apr, May & Jun, Jul & Aug, Sep & Oct, Nov & Dec, Jan & \multicolumn{2}{|c|}{ Feb, Mar } \\
\hline $8 \sim 12$ & $27 \sim 31]$ & $27 \sim 30_{7}$ & $27 \sim 30_{]}$ & $25 \sim 30$ & $25 \sim 30]$ & \multicolumn{2}{|c|}{$25 \sim 30$ ] } \\
\hline $12 \sim 16$ & $30 \sim 31-29$ & \begin{tabular}{l|l|}
$29 \sim 31$ & -29 \\
\end{tabular} & \begin{tabular}{l|l|l}
$29 \sim 31$ & 28.5 \\
\end{tabular} & \begin{tabular}{l|l|}
$29 \sim 30$ & 28 \\
\end{tabular} & \begin{tabular}{l|l|}
$29 \sim 30$ & 28 \\
\end{tabular} & 29 30 & 28 \\
\hline $16 \sim 20$ & $27 \sim 30^{\jmath}$ & 27 30 & $27 \sim 30^{\dagger}$ & 26 30 & 26 30 & \multicolumn{2}{|c|}{$26 \sim 30^{\dagger}$} \\
\hline $20 \sim 24$ & $26 \sim 28]$ & $27 \sim 28$ & $26 \sim 28]$ & $25 \sim 27$ & $25 \sim 27$ & \multicolumn{2}{|l|}{$25 \sim 27$} \\
\hline $0 \sim 4$ & $25 \sim 27-27.5$ & \begin{tabular}{l|l|}
$26 \sim 28$ & 27 \\
\end{tabular} & \begin{tabular}{l|l}
$26 \sim 27$ & -26.5 \\
\end{tabular} & 25 27-25.5 & \begin{tabular}{l|l|l|}
$25 \sim 25.5$ \\
\end{tabular} & $25 \sim 26$ & 26.5 \\
\hline $4 \sim 8$ & $25 \sim 27^{\dagger}$ & $26 \sim 27^{\rfloor}$ & $25 \sim 27^{\dagger}$ & $24 \sim 26^{\top}$ & $24 \sim 25^{\rfloor}$ & $24 \sim 25^{J}$ & \\
\hline & \multicolumn{3}{|c|}{$\begin{array}{r}\text { Relatively hot season: Day } 29^{\circ} \mathrm{C} \\
\text { Night } 27^{\circ} \mathrm{C}\end{array}$} & \multicolumn{4}{|c|}{$\begin{array}{r}\text { Relatively cool season: Day } 28^{\circ} \mathrm{C} \\
\text { Night } 26^{\circ} \mathrm{C}\end{array}$} \\
\hline
\end{tabular}


Referring back to Fig. 7(c), during the day-time in the hot season, thermal perception of natural ventilation is generally low as the air temperature is close to $30{ }^{\circ} \mathrm{C}$. Unless the outdoor climate is very windy or mechanical ventilation device is equipped, natural ventilation can hardly provide sufficient thermal comfort for the occupants. At night when the environment temperature drops to $27^{\circ} \mathrm{C}$, the chance for desirable thermal comfort increases. Better thermal vote is obtained with stronger natural ventilation, which is generally the case at higher building floor and with larger ventilation opening. The single number noise reduction of the façade including the ventilation window is about $20 \mathrm{~dB}$, which complies with the noise requirement when natural ventilation is used (Bin 2016). According to the noise guidelines, the window can operate when the day noise exposure is below $82 \mathrm{dBA}$ and night noise exposure is below 72 dBA.

In the relatively cool season, the mean temperature during day time is $28{ }^{\circ} \mathrm{C}$, which is between the two simulation cases with $T_{0}=27{ }^{\circ} \mathrm{C}$ and $30{ }^{\circ} \mathrm{C}$. Marginally acceptable thermal comfort can be expected if enough ventilation is guaranteed. During cooler night with a mean temperature of $26{ }^{\circ} \mathrm{C}$, thermal comfort could be satisfied more easily with different wind condition and opening size. It is concluded from the simulation results that expect for hot season with high day-time temperature, using double-layer ventilation window can potentially obtain thermal comfort in high-rise residential building without significantly affecting the acoustic performance. In the field experiment conducted by de Dear et al. (1991), an indoor operative temperature of $28.5^{\circ} \mathrm{C}$ was observed as the thermal neutrality, which is generally in agreement with the current simulation study.

The advantage of developing numerical solutions for analysing the thermal and acoustic performance is demonstrated in this study. As compared to experimental studies, CFD simulation produces the entire flow and temperature field of the computational domain, which is more suitable to provide insight to the ventilation analysis. The boundary conditions can be tuned flexibly, allowing a much wider parametric space to be investigated. The acoustic FEM simulation directly predicts the window noise mitigation performance with interested parameters, eliminating the cost of prototype manufacturing and expensive full-scale test. The developed simulation models offer promising tools for window design and optimization in future studies.

It should be mentioned that the present work has a number of limitations. As the CFD simulation is performed based on presumed flow conditions, the validity of the simulation result inevitably relies on assumptions. In this study, the inlet wind direction is assumed as normal to the building block, which does not take the different incidence angle into account. The building is isolated, which neglects the flow interaction with the surrounding buildings. On the other hand, the classical PMV formula is used for thermal comfort evaluation, but the parameters embedded in the formula may need revision when used in Singapore. Also the subjective assessment of indoor climate and psychological dimension of thermal comfort are not discussed in the scope of the present work. From previous field experiment studies (de Dear et al. 1991, Wong et al. 2002), the adaptive behaviour and expectations of the residents were shown to play an important role in the subjective response of thermal comfort. Having said that, as CFD simulation has already produces the whole flow field data, these effects can be readily compensated in future studies once experimental researchers come up with more suitable thermal evaluation formula.

\section{Conclusions}


This study has addressed the prediction of thermal and acoustic comfort in naturally ventilated high-rise buildings using simulation approach. The feasibility of using combined numerical models to evaluate the performance of natural ventilation has been demonstrated. It was emphasized that to evaluate the overall performance of the ventilation window, the thermal and acoustic performances should be considered together, rather than separately.

Based on the case study for a high-rise residential building, the thermal response given a set of inlet wind conditions has been systematically studied. The building floor level, window opening size, air temperature and wind speed were shown to affect the natural ventilation performance. From the simulation results, thermal comfort was more likely to elicit when the averaged indoor temperature was $28.5^{\circ} \mathrm{C}$, which was obtained with inlet wind temperature set to $25^{\circ} \mathrm{C}$ and initial wall temperature set to $30^{\circ} \mathrm{C}$. This number is close to the thermal neutrality observed by other researchers in their experimental work. The air circulation inside the unit can be controlled by adjusting the window opening size. A moderate opening size can provide sufficient indoor air flow which is necessary for thermal comfort. The opening size can be reduced when the outdoor temperature is low and incoming wind is strong to avoid overcooling.

The noise influence due to ventilation openings has been examined. The indoor noise level was determined by combining the outdoor noise exposure and façade noise insulation, simulated using empirical CRTN formula and FEM model, respectively. FEM results showed that the window sound reduction was weak at low frequencies, at about $10 \mathrm{~dB}$, and gradually increased to $15-25 \mathrm{~dB}$ at higher frequencies. Although smaller window opening exhibited slightly better SRI curve, the single number for describing effective noise insulation, rated by ISO-717, was almost the same at 13-14 dB for the three chosen opening size. With natural ventilation being implemented, the combined façade insulation for the building configuration was calculated as 19-20 dB, which was much higher than the local noise guideline of $10 \mathrm{~dB}$. To further improve the acoustic performance, passive techniques such as adding absorbing material or incorporating acoustic meta-material design concept were suggested.

For the overall performance of the ventilation window when used in Singapore, the thermal comfort was discussed by cross referencing to the local hourly temperature data recorded across the whole year. During night-time in the relatively cool seasons (from October to March), when the average night temperature is $26^{\circ} \mathrm{C}$, using ventilation window is feasible for thermal comfort, and the indoor noise level stays below $55 \mathrm{dBA}$ if the outdoor noise exposure does not exceed $72 \mathrm{dBA}$. Although this guideline can be fulfilled rather easily, a much lower noise exposure of $57 \mathrm{dBA}$ is allowed at the building façade targeting the sleeping comfort of $40 \mathrm{dBA}$ suggested by WHO. During day-time in cool seasons and night-time in hot seasons when the average temperature reaches $27-28{ }^{\circ} \mathrm{C}$, the thermal comfort is marginal as expected from the simulation results. The simulation also indicates that enhance indoor air flow can improve the thermal comfort, suggesting that incorporating combined mechanical-natural ventilation may overcome the limit of natural ventilation alone.

The limitations in the simulation approach, mainly due to the assumptions made in defining the boundary conditions and the PMV formula to calculate the thermal response, have been discussed. The study and results can be updated with more accurate measurement of input boundary conditions and more suitable thermal evaluation formula. Despite the possible limitations, the general approach is applicable to various window design studies, and serves as a promising tool for green building planning.

\section{Acknowledgements}

This material is based on research/work supported by the Singapore Ministry of National Development and National Research Foundation under L2 NIC award No. L2NICCFP12013-9. 


\section{References}

1. Aflaki, A., N. Mahyuddin, Z. Al-Cheikh Mahmoud and M. R. Baharum (2015). "A review on natural ventilation applications through building façade components and ventilation openings in tropical climates." Energy and Buildings 101: 153-162.

2. ASHRAE, S. (2007). "62.1. 2007, Ventilation for Acceptable Indoor Air Quality." American Society of Heating, Refrigerating and Air-Conditioning Engineers, Inc., Atlanta, GA.

3. Awbi, H. B. (2003). Ventilation of buildings, Taylor \& Francis.

4. Barclay, M., J. Kang and S. Sharples (2012). "Combining noise mapping and ventilation performance for non-domestic buildings in an urban area." Building and Environment 52: 68-76.

5. BCA, G. m. (2015). "Technical guide and requirements." Non-residential buildings.

6. Bin, C. K. (2016). Urban Noise Management in Singapore. INTER-NOISE and NOISE-CON Congress and Conference Proceedings, Institute of Noise Control Engineering.

7. Buratti, C., R. Mariani and E. Moretti (2011). "Mean age of air in a naturally ventilated office: Experimental data and simulations." Energy and Buildings 43(8): 2021-2027.

8. Busch, J. (1992). "Thermal responses to the Thai office environment." ASHRAE transactions 96.

9. C. M. Mak, G. S. J. (2010). "Measurement and prediction of road traffic noise at different building floor levels in Hong Kong." Building Services Engineering Research and Technology 31(2): 131-139.

10. de Dear, R. J., K. G. Leow and S. C. Foo (1991). "Thermal comfort in the humid tropics: Field experiments in air conditioned and naturally ventilated buildings in Singapore." International Journal of Biometeorology 34(4): 259-265.

11. De Salis, M. H. F., D. J. Oldham and S. Sharples (2002). "Noise control strategies for naturally ventilated buildings." Building and Environment 37(5): 471-484.

12. Evola, G. and V. Popov (2006). "Computational analysis of wind driven natural ventilation in buildings." Energy and Buildings 38(5): 491-501.

13. Fanger, P. O. (1970). "Thermal comfort. Analysis and applications in environmental engineering." Thermal comfort. Analysis and applications in environmental engineering.

14. Fanger, P. O. (1970). Thermal comfort: Analysis and applications in environmental engineering, Danish Technical Press.

15. Feustel, H. E. (1999). "COMIS - an international multizone air-flow and contaminant transport model." Energy and Buildings 30(1): 3-18.

16. Flaga-Maryanczyk, A., J. Schnotale, J. Radon and K. Was (2014). "Experimental measurements and CFD simulation of a ground source heat exchanger operating at a cold climate for a passive house ventilation system." Energy and Buildings 68, Part A: $562-570$.

17. Ford, R. and G. Kerry (1973). "The sound insulation of partially open double glazing." Applied Acoustics 6(1): 57-72.

18. Franke, J. (2007). Best practice guideline for the CFD simulation of flows in the urban environment, Meteorological Inst.

19. Huang, H., X. Qiu and J. Kang (2011). "Active noise attenuation in ventilation windows." The Journal of the Acoustical Society of America 130(1): 176-188.

20. Hurtley, C. (2009). Night noise guidelines for Europe, WHO Regional Office Europe. 
21. ISO717-1:2013 (2013). "Acoustics -- Rating of sound insulation in buildings and of building elements -- Part 1: Airborne sound insulation."

22. Kang, J. and M. W. Brocklesby (2005). "Feasibility of applying micro-perforated absorbers in acoustic window systems." Applied Acoustics 66(6): 669-689.

23. Li, Y. and X. Li (2015). "Natural ventilation potential of high-rise residential buildings in northern China using coupling thermal and airflow simulations." Building Simulation 8(1): 51-64.

24. Oldham, D. J. and X. Zhao (1993). "Measurement of the sound transmission loss of circular and slit-shaped apertures in rigid walls of finite thickness by intensimetry." Journal of Sound and Vibration 161(1): 119-135.

25. Ramponi, R. and B. Blocken (2012). "CFD simulation of cross-ventilation for a generic isolated building: Impact of computational parameters." Building and Environment 53: 34-48.

26. Sekhar, S. C. and S. E. Goh (2011). "Thermal comfort and IAQ characteristics of naturally/mechanically ventilated and air-conditioned bedrooms in a hot and humid climate." Building and Environment 46(10): 1905-1916.

27. Singapore, M. S. (2017). "Climate of Singapore."

28. Sivakumar, P., H. J. Palanthandalam-Madapusi and T. Q. Dang (2010). "Control of natural ventilation for aerodynamic high-rise buildings." Building Simulation 3(4): 311-325.

29. Søndergaard, L. S. and H. S. Olesen (2012). "Lydmæssig optimering af Russervinduer (Acoustical optimization of Supply Air Windows)." Environmental project No. 1417 Page 17-60.

30. Stephen, D. R., N. W. Gong, R. G. Leon and A. P. Joseph (2014). "Experimental characterization of full-scale naturally ventilated atrium and validation of CFD simulations." Energy and Buildings 69: 285-291.

31. Tang, S.-K. (2017). "A Review on Natural Ventilation-enabling Façade Noise Control Devices for Congested High-Rise Cities." Applied Sciences 7(2): 175.

32. Tominaga, Y., A. Mochida, R. Yoshie, H. Kataoka, T. Nozu, M. Yoshikawa and T. Shirasawa (2008). "AIJ guidelines for practical applications of CFD to pedestrian wind environment around buildings." Journal of Wind Engineering and Industrial Aerodynamics 96(10): 1749-1761.

33. Trompette, N., J.-L. Barbry, F. Sgard and H. Nelisse (2009). "Sound transmission loss of rectangular and slit-shaped apertures: Experimental results and correlation with a modal model." The Journal of the Acoustical Society of America 125(1): 31-41.

34. Wong, N. H., H. Feriadi, P. Y. Lim, K. W. Tham, C. Sekhar and K. W. Cheong (2002). "Thermal comfort evaluation of naturally ventilated public housing in Singapore." Building and Environment 37(12): 1267-1277.

35. Yu, X., S.-K. Lau, L. Cheng and F. Cui (2017). "A numerical investigation on the sound insulation of ventilation windows." Applied Acoustics 117, Part A: 113-121.

36. Yu, X., Z. Lu, L. Cheng and F. Cui (2017). "On the sound insulation of acoustic metasurface using a sub-structuring approach." Journal of Sound and Vibration 401: 190-203.

37. Zhou, C., Z. Wang, Q. Chen, Y. Jiang and J. Pei (2014). "Design optimization and field demonstration of natural ventilation for high-rise residential buildings." Energy and Buildings 82: 457-465. 